\title{
Evidentiality in Korean Conditional Constructions
}

\author{
IKSOO KWON \\ University of California, Berkeley
}

\section{Introduction}

This paper explores a seemingly non-canonical phenomenon where Korean firsthand evidential marker -te is employed in counterfactual conditionals $(\mathrm{CC}$, henceforth). The phenomenon is of special interest, since it has been claimed that evidentials are not used in irrealis clauses (Anderson 1986: 274-275). Nevertheless, this paper shows that the firsthand evidential marker does appear in Korean CCs and further, argues that to employ the firsthand envidential marker is a conceptually optimal tactic for the speaker to have cognitive distance towards the focal event in CCs. The main claim is as follows: The marker's extended function - its function of distancing and of accommodating presupposed information, not its firsthand evidential marking function, licenses the marker to be utilized in such a way.

The organization of this paper is as follows: In Section 1, background of Korean conditional constructions and that of the firsthand evidential marker's general properties are provided. In addition, the seemingly potential conceptual incompatibility between conditionals and evidentials is discussed in the section. Based on the background knowledge, this paper explores how the marker's usage conceptually fits the conditional constructions in Section 2. In Section 3, this paper models how the constructions containing the evidential marker are licensed within the Mental Spaces Framework (Fauconnier 1997, Dancygier and Sweetser 2005, Kwon 2009) to better grasp the conceptual structure of the constructions.

\section{$1 \quad$ Background}

\subsection{Korean Conditional Constructions}

Korean has agglutinative morphological system. As shown in (1), if conditional marker -myen is attached either directly to a verb stem or to declarative ending marker $-t a$, then, it forms a protasis of conditional construction (protasis in brackets [ ]): 


\section{Iksoo Kwon}

\section{(1) $[$ ney-ka o-myen/o-n-ta-myen $] \quad(k u-k a) \quad k i p p e-h a-l-t h e y n t e y$} you-Nom come-if/come-Imperf-Decl-if he-Nom be.happy-do-Fut-end Lit. If you come, he will be happy. [Neutral] "If you come, he will be happy."

Example (1) is a predictive conditional construction. Tense morphology involved here is similar to the one in English. As present tense can represent future tense in protasis of predictive conditionals in English, Korean can either utilize a null morpheme, which indicates present tense as default or a tense morpheme complex which consists of imperfective marker $-n+$ declarative marker -ta. It is noted that they are ambiguous between simple predictive conditional (e.g. if you come, ...) and quotative (e.g. if it is said that you come, ...) conditional. ${ }^{1}$ In either case, the speaker's epistemic stance toward the focal event (of the addressee's coming in (1), for instance) is neutral: The speaker does not have any kind of belief on whether the addressee is coming or not, but she naively imagines or refers to the situation where the addressee comes. In this vein, this sentence conveys the speaker's neutral epistemic stance so that it could also mean 'when you come, he'll be happy.'

Now, let us take a look at CCs where the speaker's negative epistemic stance is encoded. As in English, Korean also employs a past tense morpheme in the protasis of CCs, which can be shown as follows:

(2) [ecey ney-ka o-ass-ta-myen $]$ yesterday you-Nom come-Ant ${ }^{2}$-Decl-if (ku-ka) kippe-ha-ess-l-theyntey

\footnotetext{
${ }^{1}$ It is possible that the latter construction (-ntamyen) reads as a quotative reading and thus, it might be able to mark the speaker's distance toward the event more or less (metacomment; metarepresentation; Noh 2007), which can be shown as follows (The ambiguity can also be found when -ass-ta-myen [Ant-Decl-if] is used in the protasis):
(1) [ney-ka o-n-ta-myen] ku-ka kippe-ha-l-teyntey you-Nom come-Imperf-Decl-if he-Nom be.happy-do-Fut-end "If it is said that you are coming, he will be happy."

However, it is also true that this construction can be interchangeably used as a predictive conditional construction with the one without $-t a$ in the protasis. This paper will not discuss the ambiguity issue any further here, but the metarepresentational function of marker -ta calls for further research within the Mental Spaces Theory framework. For further discussion on which kind of epistemic stance can be conveyed, see J.-W. Park (2006).

${ }^{2}$ Following H.-S. Lee (1991), it is assumed that the marker-ess/-ass is an anterior marker, because it functions either as a past tense marker or as a perfective aspect marker depending on context. The concept of ANTERIOR can be briefly shown as follows:

... The suffix -ôss- gives a past tense meaning when in a given discourse context the speaker is concerned with the location of a given situation with respect to a reference point, as the suffix indicates that the situation takes place prior to the reference point. The suffix ôss- expresses a "completed" sense of perfective aspect when the speaker is concerned with whether the situation described has reached its end point, that is, the reference point is located either at or after the terminal juncture of a situation described (H.-S. Lee 1991: 176177). 
he-Nom be.happy-do-Ant-Fut-end

Lit. If you came yesterday, he would be happy.

"If you had came yesterday, he would have been happy."

Example (2) can be licensed when the speaker knows that the addressee did not come yesterday. In other words, the speaker conjectures an alternative world that is opposed to what really occurred in the real world, when she talks about the protasis of the examples. It is noted that the protasis used in (2) is also ambiguous in some cases in that they can be interpreted to be quotative conditionals such as If it is said that you came, he will be happy. In this respect, we can see that the fact that a protasis contains an anterior morpheme -ess does not guarantee that the utterance will be absolutely interpreted as a counterfactual reading.

In contrast, when pluperfect tense is used in the protasis of conditionals, the utterance will absolutely encode counterfactuality. This construction is equivalent to a distanced counterfactual conditional sentence in English, e.g., if he had come, she would have been happy. Likewise, in Korean, when a protasis of conditional constructions contains pluperfect tense marker -esste-, the utterance will always convey negative epistemic stance (J.-W. Park 2006: 125-126), which can be shown as follows:

\section{(3)a. [ney-ka o-ass-te-la-myen] (ku-ka) kippe-ha-ess-(u)l-theyntey} you-Nom come-Ant-Evid-End-if he-Nom be.happy-do-Ant-Fut-end Lit. If you had come, he would be happy.

"If you had come, he would have been happy."

\section{b. [ney-ka o-ass-te-la-myen] (ku-ka)*kippe-ha-l-theyntey you-Nom come-Ant-Evid-End-if he-Nom be.happy-do-Fut-end Lit. If you had come, he will be happy.}

(3a) is licensed only as a counterfactual conditional sentence: The speaker should believe that the addressee did not come. Notice that the apodosis should contain anterior morpheme and future morpheme complex. (3b) sounds ungrammatical, since the protasis frames the past event whereas the apodosis speaks of the future prediction.

Furthermore, the pluperfect tense marker seems to yield a constructionspecific meaning: Only with a protasis clause that contains the pluperfect tense complex, the speaker's regret toward the past event encoded in the protasis can be expressed. The reading conveyed by this particular construction is equivalent to I wish or If only conditional constructions in English:

\section{(4) $[k u-k a \quad o$-ass-te-la-myen ... $]$}

he-Nom come-Ant-Evid-Decl-if

Lit. If only he had come...

"If only he had come... (it would have been great)" 


\section{Iksoo Kwon}

In sum, we can learn that if a protasis contains the pluperfect tense marker, the construction will encode the speaker's negative epistemic stance and furthermore, it can encode the speaker's emotional state, i.e. regret, toward the past event as well as the speaker's negative epistemic stance.

\subsection{The Firsthand Evidential Marker in CCs}

The pluperfect tense marker, -esste-, embraces the firsthand evidential marker $-t e$. To better grasp functions of the marker -te, basic properties of the firsthand evidential marker are explored following Kwon (2009), K.-S. Chung (2006, 2007), Mary Kim (2005), J.-M. Song (1998, 2002), J.-S. Suh (1994), and I.-S. Yang (1972) among others.

The evidential marker -te encodes the speaker's acquisition of information in the past, first of all. Thus, the retrospective firsthand evidential marker -te presupposes that the focal event took place in the past and the speaker witnessed it as shown in (5):

\begin{tabular}{|c|c|c|}
\hline a. chelswu-ka & kong-ul & cha-ess-ta \\
\hline \multicolumn{3}{|c|}{ "Chelswu kicked a ball." } \\
\hline b. chelswu-ka & kong-ul & cha-te-la \\
\hline Chelswu-Nom & ball-Acc & kick-te-ending \\
\hline
\end{tabular}

By replacing the anterior morpheme with the evidential marker, the meaning of the sentence changed: In order for $(5 b)$ to be licensed, the speaker should have seen the scene where Chelswu kicked a ball in the past. The evidential marker has multiple functions, as Floyd (1999) mentioned, such as encoding firsthand evidential function, epistemic modality, irresponsibility, and emotionally indifferent state of mind (K.-S. Chung (2006, 2007), J.-S. Seo (1993)). Particularly, the semantic properties of the morpheme's encoding firsthand evidential and epistemic modality are indefeasible. The indefeasible properties can be tested as follows:

*chelswu-ka kong-ul cha-te-la, kulentey chelswu-lul
Chelswu-Nom ball-Acc kick-te-ending but Chelswu-Acc
po-ci-mos-ha-ess-ta
see-Conn-Neg-do-Ant-Decl.ending
*“(I saw that) Chelswu kicked the ball, but I didn't see him."

The second clause contradicts the first clause. Hence, we can see that the marker definitely encodes that the speaker must have observed the event that is talked about.

Regarding the epistemic modality encoded by the marker, we can see that it is also inherent, since the marker is conceptually incompatible with a weak 
epistemic adverbial probably:

$$
\begin{aligned}
& \text { (7) *amato chelswu-ka kong-ul cha-te-la } \\
& \text { Probably Chelswu-Nom ball-Acc kick-te-ending } \\
& \text { “*(I saw that) Probably, Chelswu kicked a ball." }
\end{aligned}
$$

Since linguistic element amato 'probably' encodes that the speaker does not fully vouch validity of the information that is talked about, if (7) is not acceptable, then the evidential marker should entail that the speaker vouches validity of the focal event based on his/her firsthand information source. In this vein, we can see that the marker inherently functions as an epistemic modal marker as well as a firsthand evidential marker.

\subsection{Problem Raised}

If the evidential marker presupposes witnessed factivity via its inherent firsthand evidential and strong epistemic modal characteristics as shown above, it would be natural for the evidential marker not to be used in CCs that will unavoidably make use of an irrealis event. For instance, no evidential marker in Tariana can appear in conditional constructions (Aikhenvald 2006:259).

The phenomenon is of special interest, considering that it has been claimed that "[e]videntials are normally used in assertions (realis clauses), not in irrealis clauses, nor in presuppositions..." (Anderson 1986: 274-275). Nevertheless, the seemingly incompatible combination does occur in some other languages such as Western Apache (Anderson 1986), Tucano (Aikhenvald 2002), and Mangarayi (Merlan 1981: 182). According to Anderson (1986: 277-278), the claim that evidentials are not used in irrealis clauses holds up, except for lęk'eh, which is quite common in the protasis of a conditional sentence in Western Apache, which is both irrealis as well as subordinate. An example can be excerpted from de Reuse's (2003: 90) work:

(8) Dáhayú nt'é ánailiuihi gozāā lẹkehyúgohí tsist'ōi ik'án ta' nasitnii doleet ni' nláh, tsístī hidąąhi bigha itsị 'bit, doleet ni'.

'If there were a place that had a kitchen, I would have bought some tortilla flour, because we would have eaten tortillas, with meat.'

In (8), a quotative particle lékeh is used at the end of the protasis (underlined part) and it seems that the quotative function is not in focus. Regarding this particle, Uplegger (1945: 13) described it as follows: 'as it is to be seen in mind though belonging to the past or to circumstances not actually present.' Notice that in its translation, past tense is used in the protasis: the marker's retrospective character and/or the marker's distancing function, rather than its quotative function, seems to be in focus. It might be relevant to note that as Dahl pointed out (1997: 97), there is a relationship between past tense and counterfactuality cross-linguistically. If Dahl's point is taken, it would not be implausible to say that if an evidential marker encodes retrospective aspect of 


\section{Iksoo Kwon}

an event, it will be licensed in CCs. Considering that the Korean evidential marker -te also encodes an event in past, it might not be surprising that the marker can be used in CCs. The question is how the element, which conveys both of the firsthand evidential nature and the retrospective characteristics, fits the irrealis semantics of CCs.

Based on a number of reasons, this paper argues in the following section that the use of a retrospective firsthand evidential marker in the protasis is, in fact, an optimal distancing strategy that conceptually licenses CCs in Korean (contra Anderson (1986)).

\section{Evidentials in $\mathrm{CC}$ as a Conceptually Optimal Tactic}

This paper hypothesizes that the marker's distancing function is inherited from its function of encoding a retrospective event and that it makes a conceptually optimal tactic to yield more distanced counterfactuality. To support the claim, this section discusses two major issues: First, the firsthand evidential function of the marker does not work in CCs. It appears that one of the marker's complex semantic primes - its retrospective marking - licenses the CCs conceptually. It is also shown that in fact, it is an anterior marker-ess, not the evidential marker -te, that encodes the perfectivity of the described event in the constructions, which eventually licenses the firsthand evidential marker in the construction. Second, the evidential marker's accommodating presuppositional space and distancing functions (Kwon 2009) will enable the constructions to convey more distanced counterfactuality than those without the marker, even implicating the speaker's regret.

\subsection{Retrospectivity of -Te}

Since the evidential marker encodes the speaker's firsthand source of evidence and has its strong epistemic modal properties, it would be conceptually marked, if it appears in CCs: its realis-related properties of the marker are to conceptually clash with CCs, which conjectures irrealis events. Regarding the conceptual mismatch, one significant point that native speakers of Korean made is that, intuitively, the evidential marker does not fulfill its firsthand evidential function, which can be shown in (9):

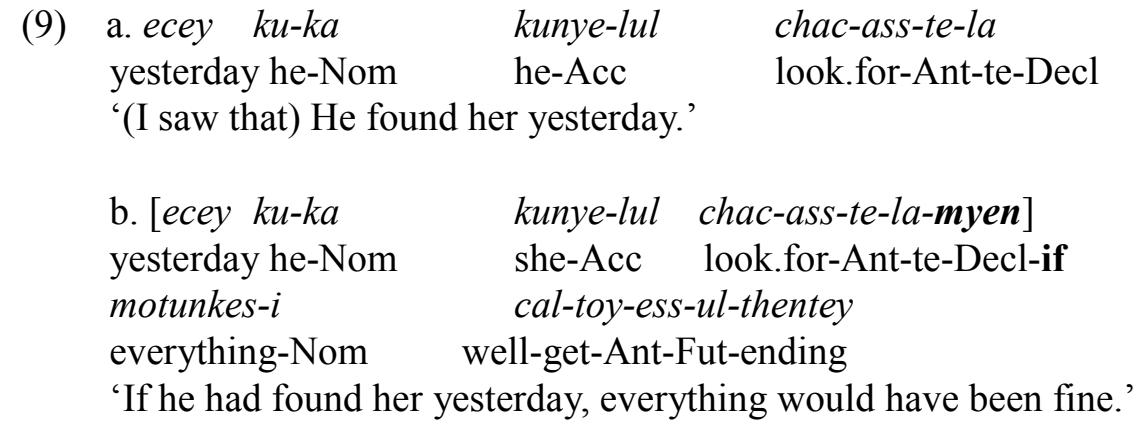


In (9a), the evidential marker encodes the speaker's firsthand source of evidence, since the utterance can only be licensed when the speaker directly experienced the focal event. However, if they are embedded in the protasis of $\mathrm{CC}$ as shown in (9b), the function does not seem to be at work: Notice that the translation is not 'If I saw that he had found her yesterday, ...,' but simply 'If he had found her yesterday, ....' In other words, source of evidence, the speaker's direct experience is already accommodated via presuppositions in the utterance. This suggests that the firsthand source marking property of the marker is not functioning or not in focus in CCs, which might enable the noncanonical construction to obviate the semantic realis-irrealis mismatch. Rather, they function as a marker presupposing occurrence of the focal event that the speaker directly experienced. In brief, its extended function is in focus - its function of accommodating presuppositional space (Kwon 2009).

Furthermore, the evidential marker cannot be licensed without anterior marker -ess/-ass in the protasis of CCs, as shown in (10):

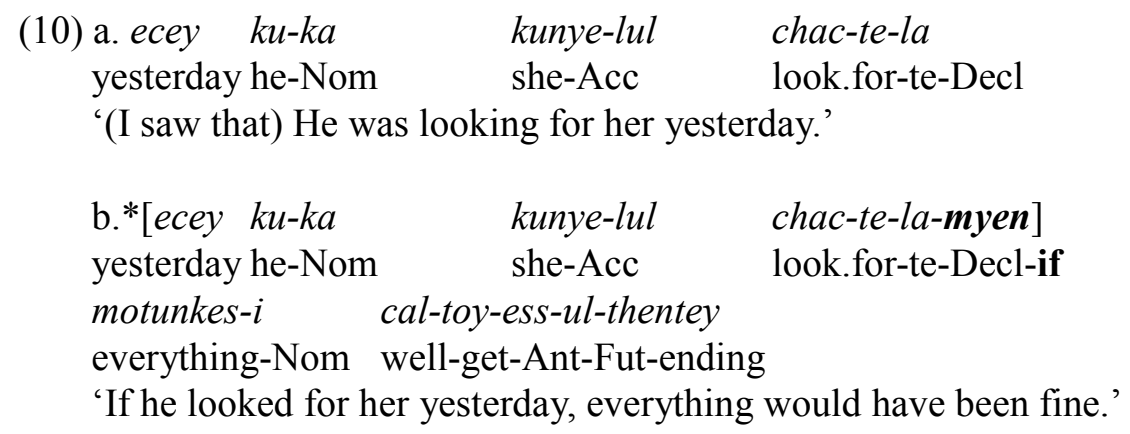

In (10a), only with the evidential marker, it can be encoded that the speaker obtained the information in question from his/her firsthand evidence, whereas sentences $(10 \mathrm{~b})$, where only the evidential marker is used in the protasis, are not even licensed at all. In other words, it is an anterior marker -ess, not an evidential marker -te that determines perfectivity of the described event and thus, that licenses CCs.

Counterfactual conjecturing is possible only when it is based on the speaker's assessment of perfectivity of an event. Conceptually, a cognizer will not able to conjecture the opposite situation of an event, unless he/she has assessed that the focal event is terminated. This is the reason why $\mathrm{CC}$ only with -te is not licensed. The evidential marker does not encode the perfectivity of the event that the speaker perceived, but the anterior marker -ess, which seems equivalent to a perfective aspect marker here, encodes it. Notice that only when the perfectivity of the event is determined and assessed by the speaker, the speaker can conjecture the counterfactuality adding the distancing morpheme $-t e{ }^{4}$ In order for the evidential marker to be licensed in CCs, the

\footnotetext{
${ }^{4}$ In a sense, it can be argued that the firsthand evidential function is still in effect, because the speaker should have completed assessment of the focal event based on the direct experience at the utterance time. However, the event within the scope of the evidentiality construction is the
} 


\section{Iksoo Kwon}

perfectivity should be presupposed with an anterior marker and thus, we can understand -te alone is not licensed with the counterfactual conditional.

\subsection{The Function of Accommodating Presupposition}

The second reason why the evidential marker's employment in CCs is optimal is that the marker accommodates what is presupposed by the speaker, that is, the fact that the speaker has directly observed a focal event. For instance, if someone says (11), it entails that the focal event occurred, as far as the speaker's memory is correct, and the speaker's assertion based on the entailment is in focus. In contrast, the fact that the speaker has directly observed the event of his having meal is presupposed:

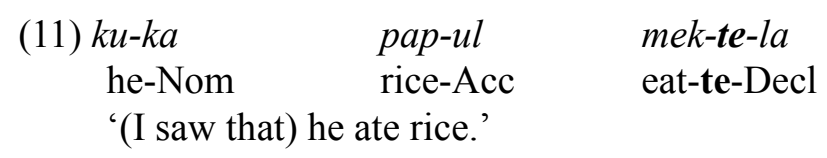

The presupposed event (the speaker's direct event perception) obtains different cognitive status from the focal event observed in the past does in that they involve spatiotemporally different indexical or deictic properties. As a result, the cognitive discontinuity between the events yields an interesting asymmetry on subject usages. That is, if a first person subject is used with the marker, then the utterance will not be natural in a normal circumstance. Since the involved events - a presupposed one and a focal one - should be discontinuous, the participants of the events should not be identical. Putting differently, it would be contradictory if the speaker objectively describes what she did in a normal context, which can be shown in (12):

$$
\begin{array}{rll}
\text { (12)? } n a y-k a & \text { pap-ul } & \text { mek-te-la } \\
\text { I-Nom } & \text { rice-Acc } & \text { eat-te-Decl. }
\end{array}
$$

'(I saw that) I ate rice.'

Nevertheless, Kwon (2009) shows that utterances such as (12) are licensed, when the subject participating the event of eating rice was a non-volitional self of the speaker. For instance, if the speaker suffers from amnesia and cannot remember what she did (e.g., ate rice), but she is observing a video that was taken of her. So to speak, in order to license the utterance, the speaker is capable of creating distance between the cognizer and the observed subject, i.e. conceptual discontinuity between the speaker and the observed subject in the event (in this case, the speaker's self) in the given context. If she is successful

one that actually did not occur. In other words, the event that the speaker directly experienced, for instance in (10b), is that he did not look for her yesterday, but not that he looked for her yesterday. If someone wishes to claim that the firsthand function is in effect, the event embedded by the protasis should be what the speaker actually experienced, not what the speaker conjectures based on what really occurred. In this respect, its firsthand evidential function is not at work, this paper claims. 
in creating the conceptual discontinuity with rich implicatures exploitable in the given context, utterances like (12) can be licensed. The conceptual distance imposed by the evidential marker is the distance between the described event and the recounting event. The marker's distancing function is conceptually salient enough to override the syntactic constraint on the subject usage that otherwise would not have licensed the utterance.

Whenever -te is used in the sentence, it is presupposed that the speaker witnessed the focal event in the past. An attested example that shows its presuppositional characteristics clearly is shown below:

$$
\begin{aligned}
& \text { aykwukca yiswunsin-un nolyang aph pata-lul palapo-te-la } \\
& \text { patriot Admiral.Lee-Nom Noryang front sea-Acc stare-te-ending } \\
& \text { "The Patriot, Adimiral Lee, Sunshin stared at the sea near Noryang." } \\
& \text { (Y.-K. Ko 2007: 203-204) }
\end{aligned}
$$

Strictly observing truth-conditional logics, no one who lives now can utter (13): in principle, since the encyclopedic knowledge that the historical figure does not exist any more in the present world and our common sense tell us that the author of the novel cannot have seen him in the past, no one should be able to make that utterance. However, it is not unnatural to use the utterance, if the author wants to describe an event in her imaginary world for the sake of vividness. What we can see here is that the marker's accommodatational character enables the author to describe an imagined event as if she had physically observed the focal event objectively in the past. Putting it differently, if someone uttered (13), we would automatically presuppose that the speaker witnessed the focal event and soon find it false. This conforms to what Lambrecht has pointed out (1996:78): what the interlocutors have in common is not a presupposition of existence of the historical figure, but the mental representation of the figure in the presupposed mental space. As with other presuppositions (e.g. the existence of the King of France in The King of France is bald), the question of whether the speaker observed the figure or not is infelicitous to talk about, since it is already presupposed by the speaker. ${ }^{5}$

In sum, this section has shown that in fact, there are more than a few cases where the marker's distancing function based on its function of accommodating presupposed information is more salient over the other functions, and where the marker's firsthand source encoding function might not be in focus. If the marker's primary function, its firsthand source encoding function, is not in effect for whichever reason and thus, only its distancing function remains to function, it will be definitely an optimal lexical item for CCs: Its retrospective marking and distancing functions conspire to encode

\footnotetext{
5 The cognitive motivation of the phenomenon is, however, never clear. There are two possibilities: First, the firsthand marker's primary function encoding the firsthand source is simply bleached out as a result of its undergoing grammaticalization process. Second, the primary function of the marker is suppressed by the irrealis characteristic of the CCs. The thing is that, only with the fact that -te alone cannot be licensed in CCs, it might not be clear to decide which scenario is the motivation, which calls further research.
} 


\section{Iksoo Kwon}

more distanced counterfactuality in the constructions.

\section{$3 \quad$ Mental Spaces in Evidentiality of CCs}

Within the Mental Spaces Theory framework (Fauconnier 1997; Dancygier and Sweetser 2005), this section argues that these seemingly non-canonical phenomena can be accounted for in an elegant and consistent fashion. Particularly, this section argues that in addition to Dancygier and Sweetser's way of representing CCs in terms of darkening blocks in Mental Spaces diagrams, the distancing strategy in the CCs should be represented by layering blocks.

\subsection{Mental Spaces in Korean Conditional Constructions}

Following the Mental Spaces models demonstrated by Dancygier and Sweetser (2005), we can account for Korean conditional constructions in terms of the models, which can be shown in (14).
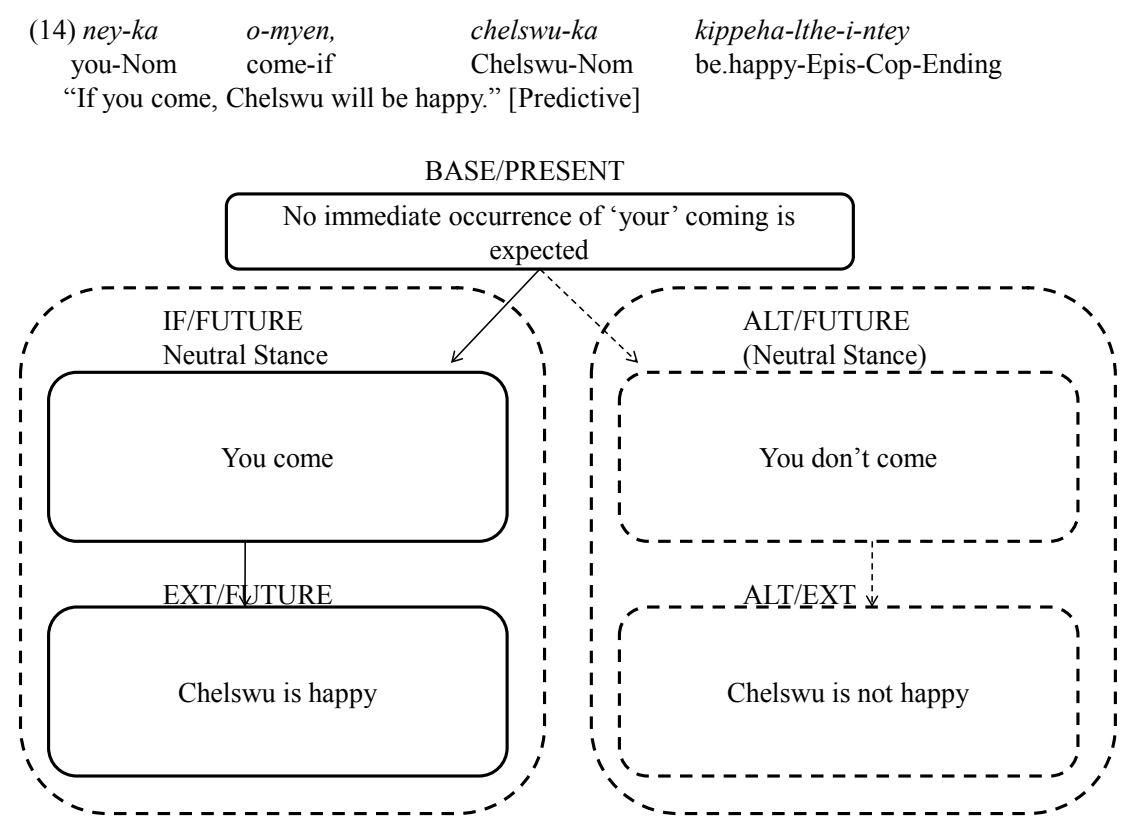

(14) is an example of conditional constructions where the speaker poses a neutral epistemic stance toward the event. That is, in order to utter (14), the speaker does not have to presume either that the addressee will not come or that the addressee will come. Since the speaker's epistemic stance is neutral, there is no imminent occurrence of the focal event of the addressee's coming presupposed in the base space. In IF/FUTURE space, the event in the protasis is a sufficient condition for the event in the apodosis, on the one hand. On the other hand, in ALTERNATE/FUTURE space, the event of the addressee's not coming is in the protasis and the event of the opposite result is in the apodosis, which form a complete sentence where the former is also a sufficient condition for the latter. 
Now, let us take a look at an utterance where anterior marker -ess/-ass is used. As mentioned in the previous section, since an anterior morpheme affects the temporal domain of the protasis so that the protasis conjectures a mental space where what really happened in the real world did not happen, the utterance will convey counterfactual reading. This explains why perfectivity goes well with counterfactual reading: Based on the speaker's knowledge on what happened in the past in the real world, its alternative space can be conjectured. Let us take a look at (15).
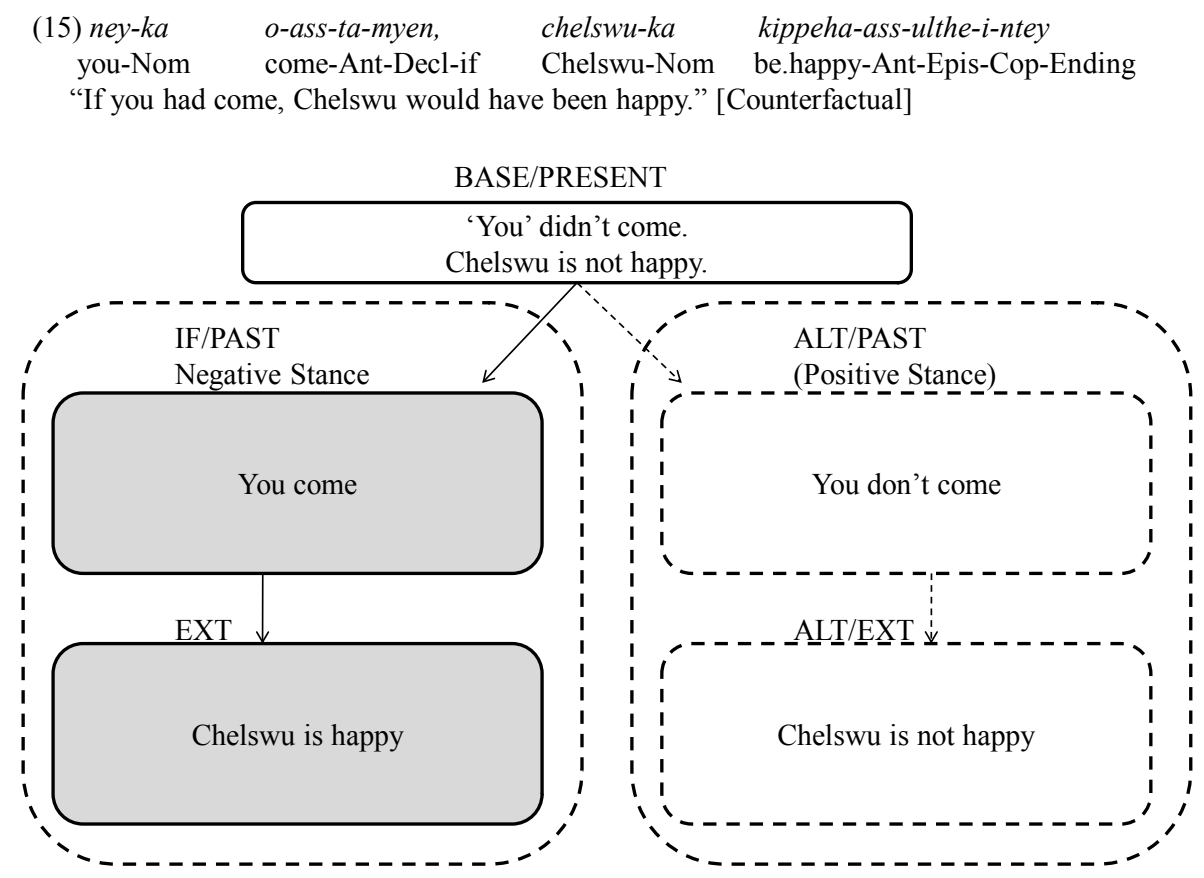

Following Dancygier and Sweetser's (2005) way to represent the counterfactuality, we can darken the blocks involved in IF/PAST space as shown in (15), indicating that the contents represented by the darkened blocks result from the speaker's conjecturing the opposite to what really happened.

\section{2 -Te in CCs}

Based on the background discussions on Korean conditional constructions, now we can elaborate our model for the firsthand evidential marker -te in CCs. It has been shown in the previous section that the marker's firsthand evidential marking function is not in focus in CCs, but rather, its distancing function is taken advantage of in the constructions. Due to the marker's functions of distancing and accommodating presuppositional space, the marker's appearance in the protasis can also be represented by creating a layer in the diagram. Let us look into an example, which can be shown in (16).

In the protasis of (16), the focal event block is distanced by creating a layer of firsthand evidential space. Moreover, both the firsthand evidential 


\section{Iksoo Kwon}

space block and the focal event block are darkened. Comparing it to (15), we can learn that (16) can convey more distanced counterfactuality, since the speaker's negative epistemic stance toward the focal event is encoded by the anterior marker and at the same time, the negative space is further distanced by the firsthand evidential marker's function of accommodating presuppositional space. Notice that in ALTERNATE/PAST space, the event of the addressee's not coming, not the event of the speaker's not witnessing the focal event, is conjectured. The fact that the focal event space, not the firsthand evidential space, is negated in the ALTERNATE space supports the claim that the firsthand evidential marker functions only as a distancing item to accommodate presupposition.
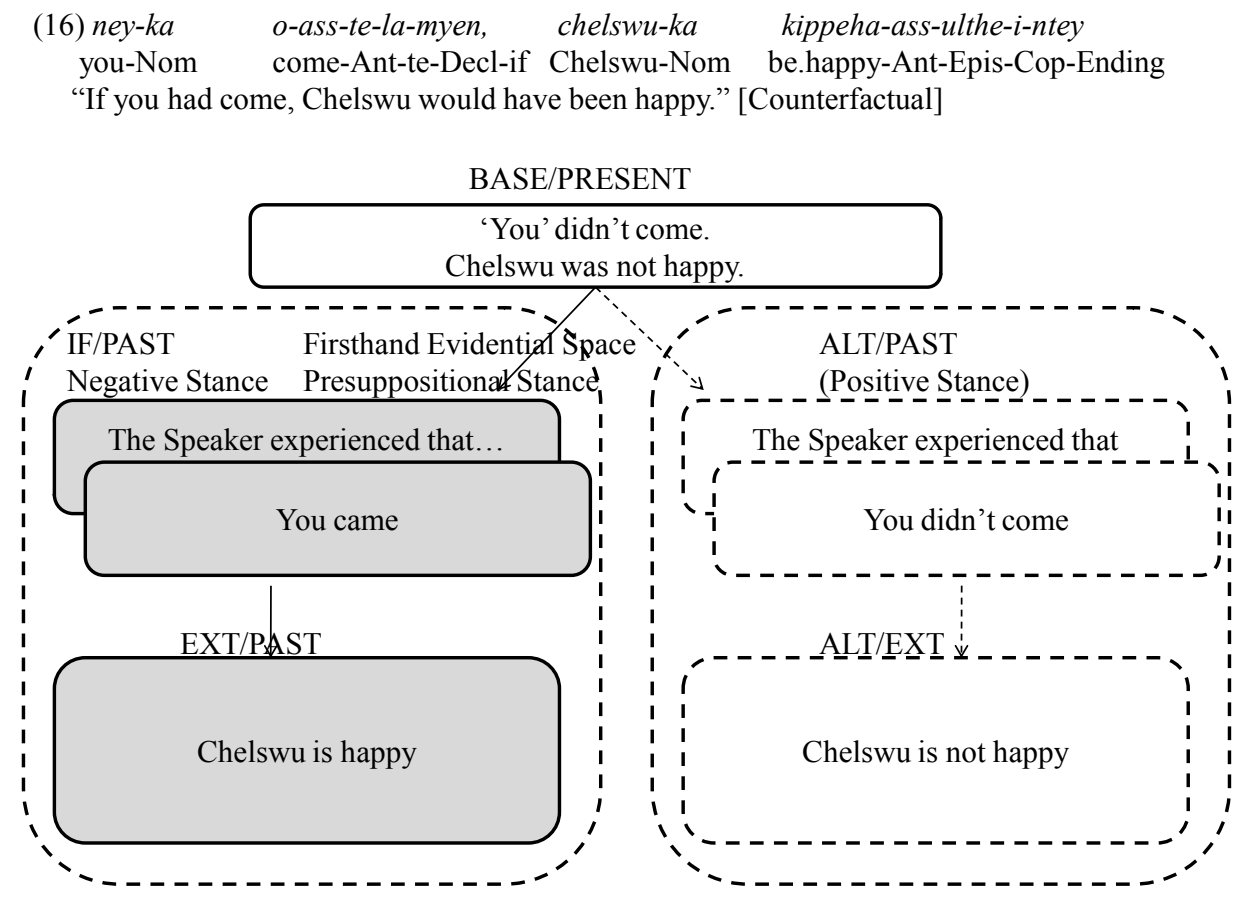

In sum, CCs where the firsthand evidential marker appears yield more distanced counterfactual reading than CCs where it does not, because the marker will create conceptual distance between the speaker and the focal event by accommodating presuppositional space and thus, the focal event whose counterfactuality has already been marked by the anterior morpheme -ess- is even to be further distanced by the firsthand evidential marker's distancing characteristics. The doubly distanced focal event naturally and compositionally yields more distanced counterfactuality.

It seems that the CCs can be configured with two major parameters. The first parameter is that the target event is conceptually the one that has been completed so that its counterfactuality can be conjectured. The second one is that the target event is conceptually distant from the speaker. In this respect, the phenomenon that the retrospective firsthand evidential marker -te- is employed in CCs might not be unintuitive and unnatural, but rather optimal, 
since the evidential marker originally has its retrospective marking function and its accommodational character. Although we cannot be sure whether the marker's firsthand source marking function is bleached or suppressed, but it is sure, at least, that the marker's primary function is not in focus when it is used in the protasis of CC.

More intriguingly, the morpheme complex -asste- can encode farther distanced counterfactuality so that it oftentimes depicts the case where the speaker was regretful toward an event in the past where she should have done something, but she couldn't, only with the protasis. This can be paraphrased to be if only constructions in English, which can be exemplified in (17).
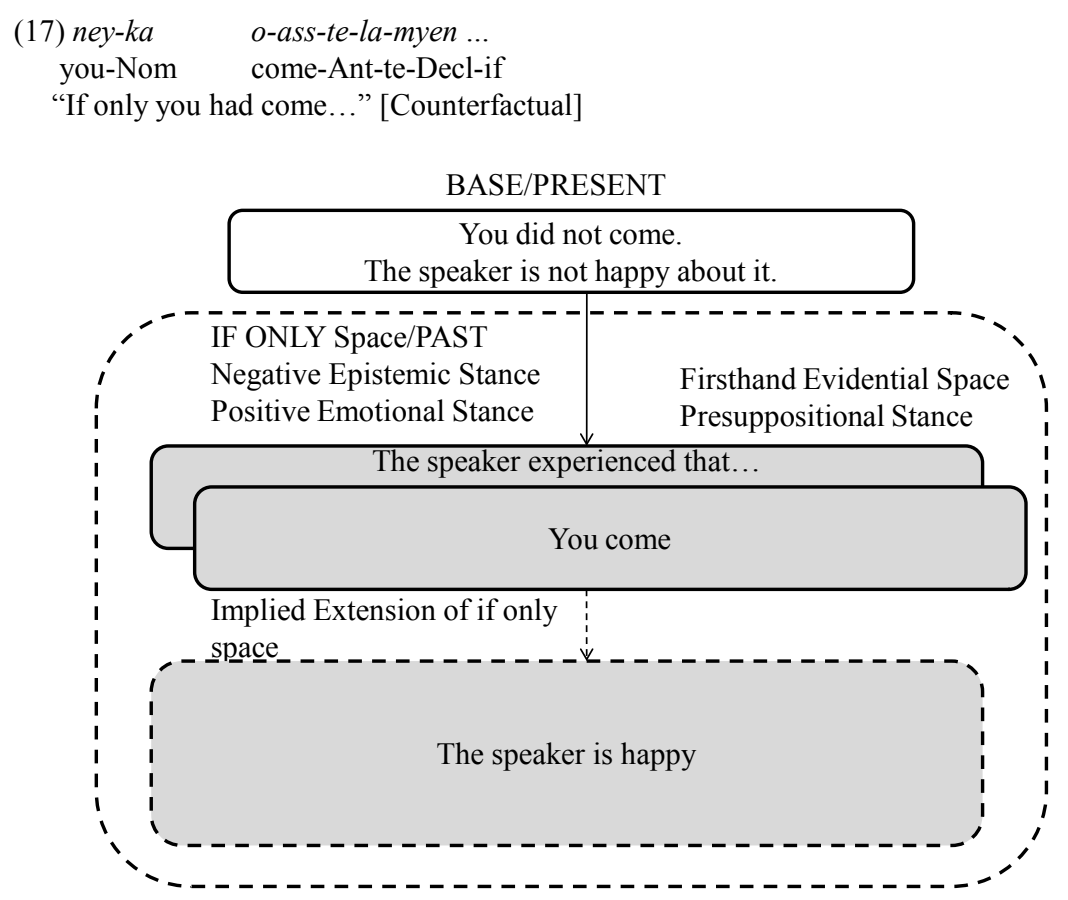

Since the utterance consists of the protasis only, which has an anterior marker and the evidential marker, we only need one meta-mental space to represent the protasis. In the similar mechanism shown in (17), the evidential marker creates conceptual distance between the speaker and the conjectured focal event of the addressee's coming. Then, implied extension of the protasis which is potentially given in the context can be linked afterwards and finally, the utterance will encode the speaker's regret.

\section{$4 \quad$ Concluding Remarks}

This paper showed that a Korean firsthand evidential marker -te is employed in counterfactual conditional constructions, which is conceptually unexpected, since it has been claimed that evidentials are normally used in realis clauses, not in irrealis clauses, nor in presuppositions. Nevertheless, this paper showed that the firsthand evidential marker does appear in Korean CCs and actually, 


\section{Iksoo Kwon}

argued that employing the firsthand envidential marker in CCs is a conceptually optimal tactic for the speaker to distance the focal event.

In the last section, the paper modeled Korean conditional constructions in general and Korean CCs that contain the evidential marker within Mental Spaces Theory (Fauconnier 1997, Dancygier and Sweetser 2005, Kwon 2009). Particularly, this paper proposed that representing layers created by tense complex (anterior marker -ess/-ass and firsthand evidentiality marker -te) will be of great help in grasping elaborately varying degrees of counterfactuality.

\section{References}

Aikhenvald, Alexandra Y. 2006. Evidentiality. Oxford: Oxford University Press.

Aikhenvald, Alexandra Y. 2002. Language contact in Amazonia. Oxford: Oxford University Press.

Anderson, L. B. 1986. Evidentials, Paths of Change, and Mental Maps: Typologically Regular Asymmetries. In W. Chafe and J. Nichols, eds., 273312. Norwood, New Jersey: Ablex.

Chung, Kyung-Sook. 2006. Korean Evidentials and Assertion. In Donals Baumer, David Montero, and Michael Scanlon (eds.). Proceedings of the $25^{\text {th }}$ West Coast Conference on Formal Linguistics, 105-113.

Chung, Kyung-Sook. 2007. Spatial Deictic Tense and Evidentials in Korean. Nat Lang Semantics 15, 187-219.

Dahl, O. 1997. The relation between past time reference and counterfactuality: A new look. In A. Athanasiadou and R. Dirven, eds., On Conditionals Again, 97-114. Amsterdam and Philadelphia: John Benjamins.

Dancygier, Barbara and Eve Sweetser. 2005. Mental Spaces in Grammar: Conditional constructions. Cambridge: Cambridge University Press.

De Reuse, Willem J. 2003. Ch. 4. Evidentiality in Western Apache. In Aikhenvald, A. Y. and R. M. W. Dixon. eds., 79-100. Amsterdam / Philadelphia: John Benjamins Publishing Company.

Fauconnier, Gilles. 1997. Mappings in Thought and Language. Cambridge: Cambridge University Press.

Kim, Mary Shin. 2005. Evidentiality in Achieving Entitlement, Objectivity, and Detachment in Korean Conversation. Discourse Studies 7, 87-108.

Ko, Yeong-Keun. 2007. Hankwukeuy Sicey, Sepep, Tongcaksang [Tense, 


\section{Evidentiality in Korean Conditional Constructions}

Mood, and Aspect in Korean]. Kyeonggi-do, Korea: Taehaksa.

Kwon, Iksoo. 2009. The Korean Evidential Marker -te Revisited: Its Semantic Constraints and Distancing Effects in Mental Spaces Theory. Paper presented at Fillmore Fest 2009: Frames and Constructions, University of California, Berkeley, July 31-August 2, 2009.

Lambrecht, Knud. 1996. Information Structure and Sentence Form: Topic, Focus and the Mental Representations of Discourse Referents. Cambridge: Cambridge University Press.

Lee, Hyo-Sang. 1991. Tense, Aspect, and Modality: A Discourse-Pragmatic Analysis of Verbal Affixes in Korean from a Typological Perspective. Ph.D. dissertation. University of California, Los Angeles.

Merlan, F. 1981. Some functional relations among subordination, mood, aspect and focus in Australian languages. Australian Journal of Linguistics, $1,175-210$.

Park, Jeong-Woon. 2006. Epistemic Stance in Korean Conditional Sentences. Discourse and Cognition 13.2, 109-132.

Seo, Jeong-Soo. 1993. Tasi \{-Te-\}lul Chacase [Finding \{-te-\} Again]. kukehak [Korean Linguistics] 23, 255-323.

Song, Jae-mog. 1998. Anmaycumssikkuth 'te-'uy uymi kinungey tayhaye: yuhyeonglon- cek kwancemeyse [On Semantic Function of Imperfective Marker '-te-': From a Typological Perspective]. kukehak [Korean Linguistics]. 135-169.

Song, Jae-Mog. 2002. A Typoloical Analysis of the Korean Evidential Marker '-Te-.' Enehak [The Linguisitic Society of Korea] 32, 147-164.

Uplegger, F. J. 1945. Thesaurus of Apache language forms. Manuscript, $47 \mathrm{pp}$. San Carlos Lutheran Mission Library, Peridot, Az.

Yang, In-Seok. 1972. Korean Syntax: Case Markers, Delimiters, Complementation, and Relativization. Baykhap Publishing. Co.

Iksoo Kwon

University of California, Berkeley

Department of Linguistics

1203 Dwinelle Hall

Berkeley, CA 94720-2650

kwoniks@hufs.ac.kr 